\title{
MIND THE GAP - THE IMPORTANCE OF REFLECTING ON DIFFERENT NOTIONS OF LEARNING AND KNOWLEDGE WITHIN AND BETWEEN COGNITIVE AND EDUCATIONAL SCIENCES
}

\author{
Brigitte Römmer-Nossek \\ University of Vienna, Austria \\ E-mail: brigitte.roemmer-nossek@univie.ac.at
}

\begin{abstract}
Cognitive and educational sciences share a fundamental interest in learning. While theoretical bases and practical interests seem to match well at first sight, it is well worth to take a closer look. In the different disciplines involved in the Cognitive Sciences there is a large number of approaches to study learning, but closer glance reveals a limited number of ways to conceptualize learning. In its short history, the field has seen some paradigm shifts, which changed the way we look at human cognition and thus at learning. It is worth noting that each paradigm also transports an implicit notion of knowledge.

In the field of education we find these paradigms as different learning theories, which in turn determine approaches to teaching and learning. Dealing with knowledge is central to educational practice. Furthermore, educational research indicates that our personal concept of knowledge qualitatively influences the way students learn. Thus there is a deep, but the intricate relationship between our concepts learning and knowledge.

If the interaction between the two fields is to go beyond the (often unsatisfying) attempt to find directto-classroom recipes, explicit concepts of learning and knowledge must be the starting point for any successful interdisciplinary collaboration.
\end{abstract}

Key words: cognitive sciences, education, knowledge, learning.

\section{Introduction}

Cognitive Sciences and educational sciences are both concerned with the phenomenon of learning.

The division of labour seemed to be clear: educational sciences are concerned with learning in educational systems while cognitive sciences are involved in basic research of learning. Recently, however, there is a growing interest within the cognitive sciences in learning in educational systems.

This raises the question about the nature of the relation between basic research and application. Reif (2008) states that a "truly scientific approach to education would thus need to strive for a better understanding of the underlying human thought processes and knowledge required for a good performance in particular scientific domains. Such an approach would then deliberately exploit an understanding of these underlying mechanisms to help students learn." (Reif, 2008, xiv) While there will not be much discontent on the idea that a better understanding of the human mind may contribute to developments in educational systems, the statement suggests that education can be grounded in scientific findings in a rather straightforward way: 
PROBLEMS

OF EDUCATION

IN THE $21^{\text {st }}$ CENTURY

Volume 46, 2012

124

Basic research uncovers how humans think which in turn informs education how to teach.

At first glance the notion that basic research will "inform" educational practice may seem appealing, at a second glance the relation is more complex. Ansari and Coch (2006), argue that direct-to-classroom application have proven to be difficult and often unsatisfying. At the same time persistent 'neuromyths' lead to the simplification or misinterpretation of scientific findings, culminating in approaches such as 'brain based learning'. They diagnose that the current situation for a cooperation between education and cognitive (neuro-)science is characterized by a lack of a common language and background, few contacts and a lack of a common forum and funding opportunities. They conclude that currently there is no common framework.

A more optimistic view can be found with Meltzoff et.al. (2009), who see the dawn of 'a new science of learning': "A convergence of discoveries in psychology, neuroscience, and machine learning has resulted in principles of human learning that are leading to changes in educational theory and the design of learning environments."

Meltzoff et al. (2009) essentially propose that learning is computational and social interaction acts as a catalyst for learning through imitation, shared attention, and empathy and social emotions providing an adequate input to the learning mechanism.

While this view is in line with state of the art research in the cognitive sciences and immediately appealing for researchers with a similar background, the question remains whether in practice this approach can live up to its promises. At a closer glance, education, rather than being a partner at eye-level, seems to provide the playground.

Beyond Meltzoff and colleagues' approach, there are various ways to approach the phenomenon "learning" in the disciplines involved, and the question is whether they are mutually compatible. In order to come closer to a common framework, an obvious first step is to take a look at how learning is conceptualized.

The perspective taken for this theoretical paper is that of a cognitive scientist and higher education professional. As point of departure, core concepts of learning theories as represented in textbooks or mainstream publications will be identified as well as their respective level of formalization.

Based on this, it will be shown which concepts of learning relate to which paradigms in cognitive science. It will be argued that different approaches to the question 'how the mind works' implicitly carry different notions of knowledge and that this matters for learning, because educational research has shown that the individual conceptualization of knowledge influences learning in quite fundamental ways. Based on this, some implications for practice may be considered.

\section{Concepts of Learning}

Terminology may differ between schools and disciplines, therefore an attempt to compare approaches to learning seems to be most efficient when focusing on underlying concepts.

The discipline which is most rigid in the sense that a concept is implemented as a mechanism, i.e. an algorithm or a simulation, is computer science. Logical systems learn by inference, systems of classical artificial intelligence store and retrieve from memory, and artificial neural networks learn by association, by representing the statistical properties of their input (their environment). So here we find three approaches to learning: inference, storage and retrieval, and association.

Learning in natural neural networks (a.k.a. in the brain), is realized through continual reorganization of synapses, so again the learning mechanism is association. Biology adds an evolutionary perspective and adaptation as theoretical framework for learning. Please note that we are not talking about an implementable mechanism or precise model any more. 
Brigitte RÖMMER-NOSSEK. Mind the Gap - the Importance of Reflecting on Different Notions of Learning and Knowledge within and between Cognitive and Educational Sciences

The question whether we are talking about a mechanism, a model, a theory, or a metaphor becomes even more pressing when looking at the discipline concerned with learning: psychology. Much-maligned behaviourism, while explicitly rejecting to explain the "black box", is making the strong assumption that the mind is a tabula rasa which is being filled through the association of stimuli (Zimbardo, 2004). It is thus well-compatible with those disciplines which want to explain the workings of the "black box" by focusing on association as learning mechanism. It should, however be noted that in neuroscience and computer science the mechanism of association is very concrete, whereas behaviourism observes changes in the behaviour of the whole organism.

In Cognitive Psychology, which still constitutes the mainstream, the concept of learning boils down to the storage and retrieval of contents. Research focusses around memory and its capacity (Zimbardo, 2004). It is therefore well compatible with the classical artificial intelligence direction of computer science, but also in the field of neuroscience there is much talk about the brain storing and retrieving.

Other approaches in psychology remained, albeit less hegemonic. Gestaltpsychology conceptualizes learning as insight learning, as the recognition of an organizing principle (Gestalt) which then leads to new approaches in problem solving. In experiments insight learning was primed by allowing subjects to interact with artifacts in the environment before a problem was posed (Wertheimer, 1982). Yet another approach can be found in Vygotsky's (1978) work, who saw learning as internalization: The learning process is initially driven by an activity in the physical environment, which by means of social interaction is transformed from an inter- to an intrapersonal process.

This very brief overview shows that while a common interest is being shared, there is no comprehensive concept of learning. Learning is being conceptualized as association, storage and retrieval, inference, adaptation, insight, or internalization. Furthermore, the level of formalization differs dramatically. Only the former three have been implemented as concrete mechanisms. The existence of such divergent concepts of learning raises the question whether they are mutually compatible and which ones will be more viable.

\section{Learning, Knowledge and Paradigms in the Cognitive Sciences}

In spite of today's cognitive sciences being a young field of research, it has already undergone dramatic paradigm shifts (for a detailed historical account see Bechtel et al. 1998; Varela 1990). The different paradigms show differences in compatibility with different concepts of learning. If we assume that the failure of a research program may be an indicator for the viability of the concepts involved, it is worthwhile to have a closer look.

Early or classical cognitive science united psychology, philosophy, linguistics, and classical artificial intelligence (computer science) under the postulate that 'cognition is information processing'. This cognitivist position essentially treats learning as storage and retrieval of memory contents and thinking as logical inference. It can be understood better if one considers that for the first time a new and powerful instrument was available which allowed for testing for coherence theories (at least those which could be cast in an algorithm) as well as prediction of experimental findings: the digital computer. However, if the computer is taken as a model for human cognition, one implicitly transports a notion of knowledge which is built on the distinction between syntax and semantics. The price for this was that the resulting models were closed formal systems, which could solve problems within a particular domain, but did not show properties of human cognition such as the ability to act based on incomplete knowledge about a situation or the ability to change an unsuccessful strategy. For a while there was hope that implementing 'real world knowledge' into these systems, but in the end the classical approach must be called a failure. 
PROBLEMS

OF EDUCATION

IN THE $21^{\text {st }}$ CENTURY

Volume 46, 2012

126

The notion of knowledge which was implicitly transported is that knowledge consists of separable units which can be decontextualized and contextualized, stored and retrieved without qualitative change, and which describe the world. A necessary presupposition was that knowledge "in the mind" and "in the world" are somehow similar. While 'knowledge' is not part of the terminology in the cognitive sciences, which would rather speak of 'information', pedagogical implications are still clear: Learning storing and retrieving knowledge, which is, in a sense, objective und unchangeable, new knowledge can come about through inference. It is a purely intellectual act, the body (including emotions) and social environments may at best have to role of a "motivator".

Among other fundamental problems of this approach, it must be noted that the computer models of this early phase did not learn. Thus there was no convincing answer to the question how knowledge "in the mind" relates to the world (for a detailed critique see for example Dreyfus, 1979; Peschl, 1994). Again it was a methodological innovation which brought about change: In the mid-1980 Rumelhart and McClelland (1986) published a collection of research papers dealing with a new type of computer model: artificial neural networks (NN). These connectionist models were inspired by brain networks and consisted of a number of identical units, highly simplified models of neurons, and weights, which would determine the "synaptic" strength of the connection between the units. The most striking feature of a NN perceived at the time was that the performance on a particular task can be tuned in a training process using algorithms which incrementally change the weights - they can learn. It would go beyond the scope of this paper to go into the technicalities of these models and their relation to real neural networks (for a detailed account see Churchland and Sejnowski, 1993), relevant in this context are the, again implicit, implications of connectionism for the notion of knowledge.

In (artificial) neural networks, knowledge is not "stored". There is no separation of semantics and syntax, the network is its knowledge (Clark, 1999). The relation of 'the learned' to the world is no longer problematic, since it came about through interaction with the environment. What should be noted, however, is that while there may be some topographical mapping, it is not an image of the world, the network merely needs to produce adequate behaviour in interaction with the world - this is very close to the concept of coupling of Maturana and Varela (1970). Thus learning does not mean to "copy" separate units of knowledge, but to acquire the ability to produce adequate results by association inputs with desired outputs.

In the 1980ies this new way to model the mind was conceived to be a revolution, in retrospect it was only the beginning of thinking of human cognition in a fundamentally different way. It became possible to question whether it is evolutionary plausible that the brain's function is to faithfully store and retrieve 'objective' information about the world. Instead, the role of cognition is to produce viable predictions and behaviour for a body interacting with and within a physical and social world (Varela, 1990; Clark, 1994; Glenberg, 1997).

The fact that humans have a body on the one hand constrains what can be done within this world, e.g. our arm has only so many degrees of freedom thus our cognitive apparatus will come up with a number of predictions and behaviours which is limited accordingly. On the other hand, the interaction of the body with the environment may support what is traditionally thought of as a rather abstract cognitive operation, e.g. using the fingers to count for addition (Dahaene, 1997). In this sense cognition is embodied.

A distinguished characteristic of humans is that we tend to structure and build our environments, often in a way that 'cognitive load' is being reduced (Clark, 1994) For example, by carrying a schedule with all our appointments, we are 'offloading cognitive load': we replace having to memorize a large number of dates by interacting with this artifact whenever needed. Environments are structured by physical artifacts as well as social conventions organizations and - last but not least - language. This "ultimate artifact" has a referential function which allows to stabilize (parts of) our memory and to negotiate the structuring of our environment 
Brigitte RÖMMER-NOSSEK. Mind the Gap - the Importance of Reflecting on Different Notions of Learning and Knowledge within and between Cognitive and Educational Sciences

(Clark, 2001). New generations will not only inherit genes, they grow into physical, social and organizational structures, Clark (1994) refers to this as scaffolding.

The implications of an embodied and situated view on cognition for a traditional notion of knowledge are shattering: knowledge as a static entity describing a part of the world is not a plausible option anymore. Artifacts like books may invite stable patterns of interaction and thus contribute to the illusion of objective knowledge. Knowledge is better conceptualized as an ongoing process of negotiation which encompasses the coupling of mental, physical as well as social structures and processes.

What it means "to know" changes dramatically, since the ability to faithfully reproduce an artifact will no longer suffice, it is the ability to actively participate in knowledge processes.

Please note that this approach does not refute connectionism, association is still considered to be a viable learning concept. In this light, Meltzoff's et al. (2009) proposal that learning is essentially computational and that social interactions act as catalysts is well compatible with the paradigm introduced above.

However, while it may suffice for the cognitive scientist, who strives for an explanation at the level of a mechanism, the explanatory power of association as the only formalized learning concept considered seems rather limited for educational theory as well as practice. If cognitive and educational science are to collaborate successfully, there needs to be reflection on the theoretical level and a mutual agreement for the concrete project, with regard to the question which concepts of learning and knowledge will yield explanatory power with regard to the research question or application.

Considering the complexity of educational processes 'in the wild' the works of Wertheimer (and Gestalt psychology in general) and Vygotsky deserve a wider perception by the cognitive science community, since, in a sense they anticipated the current paradigm, as well as the works of Piaget.

\section{Where Educational and Cognitive Sciences Touch}

Why should a paradigm shift in an interdisciplinary field of research be of interest for educational science? After all, all the learning theories the cognitive sciences have seen, can be found among the different learning theories.

The information processing metaphor deeply diffused into our everyday language, talk about storing, retrieving and processing can be heard everywhere. As argued above, this invites to think of knowledge as separable units which have an air of objectivity. (And it fits well with Western philosophical traditions which see a divide between mind and body, also referred to as the mind-body problem.) The ability to faithfully reproduce a 'knowledge artifact' may be a necessary competence for an individual to participate in knowledge processes, but it is not the ability to actively participate in the negotiation of knowledge.

While in the literature on higher education one will rarely find explicit concepts of learning and knowledge, some research indicated that an intricate link exists between the individual conceptualization of knowledge and the learning strategy chosen.

A wide spread dichotomy is the differentiation of a surface vs. a deep learning approach, found by Marton and Säljö (1976, cited in Biggs, 1999): Surface learning relies on memorizing with a focus on facts and routines. Rules and formulas are used for problem solving, while facts and concepts are linked - if linked - without reflection. The motivation to learn is extrinsic. Deep learning, on the contrary, is intrinsically motivated through the search for meaning. The focus goes to the essential elements of a given problem and the central arguments. The learner links theory and personal experience, old and new knowledge. Entwistle and Ramsden (1983) added an intermediate learning style, namely strategic learning, which aims at good performance through grades. 
PROBLEMS

OF EDUCATION

IN THE $21^{\text {st }}$ CENTURY

Volume 46, 2012

$\frac{\text { Volume } 46,2012}{128}$

One cannot help but notice the compatibility of surface learning with the object oriented approach to knowledge in classical cognitive science. Knowing is understood as faithful reproduction, whereas the deep learner's search for meaning can be seen a negotiation process. Perkins (2008) offers an account of knowledge conceptions which is well compatible with the implicit notions of knowledge implicitly transported through the three paradigms of cognitive sciences: He differentiates between possessive, performative, and proactive knowledge and argues that each conception results in a particular learning style. Possessive knowledge conceptualizes knowledge as information, as "money in the cognitive bank" (Perkins, 2008, 4). Students holding this view will adopt a surface learning approach, holding the illusion that possession will produce understanding.

Performative knowledge is "knowledge-as-understanding" which aims at acting based on possessive knowledge. This view will trigger a strategic or even deep learning approach, but the knowledge acquired will not be easily transferred. A proactive conceptualization of knowledge requires the adoption of a deep learning strategy. It again includes the former stage and goes beyond it in the sense that it involves an alert and lively use of knowledge, which can potentially be transferred.

\section{Implications for Educational Practice}

It seems obvious that students' conceptions of knowledge are influenced by their teachers. The impact caused by assessment and teaching methods on students' learning cannot be overestimated, since the mode of examination will determine what students will do and which learning style will be appropriate in order to pass the course (Biggs, 1999). In the light of the arguments above one may also conclude that the assessment method chosen implicitly transports a notion of knowledge as well, e.g. consider the multiple choice test, - format which is notorious for inviting surface (or bulimic) learning. Very high skills in test construction in demand in order to go beyond the recall, or simply recognition, of separate facts in this mode of examination.

While teachers usually start thinking about their courses starting with contents, then consider appropriate teaching methods, and finally the mode of examination. Therefore Fink (2003) proposes a backwards design of courses starting with the assessment methods and the questions what students should still know or be able to do five years after completion of the course. The ability to reflect conceptions of knowledge against findings from cognitive sciences may support teachers in making decisions in the context of their discipline and general teaching environment. This is well in line with Schön's notion of the reflective practitioner (Schön, 1983).

If the interaction between the educational and cognitive sciences is to go beyond the (often unsatisfying) attempt to find direct-to-classroom recipes, explicit concepts of learning and knowledge must be the starting point for any successful interdisciplinary collaboration.

\section{Conclusions}

In the cognitive sciences there is a growing interest in the field of education. While some see the foundations of a new science of learning laid, others state a failure of direct-to-classroom application of basic research findings and the lack of a common framework. Assuming that a common understanding of the notions of learning and knowledge are central to such framework, a closer look reveals a limited number of learning concepts, namely association, storage and retrieval within the information processing metaphor, adaptation, learning as productive thinking (Wertheimer), and as internalization (Vygotsky).

In its short history, cognitive science underwent two paradigm shifts, from classical 
Brigitte RÖMMER-NOSSEK. Mind the Gap - the Importance of Reflecting on Different Notions of Learning and Knowledge within and between Cognitive and Educational Sciences

cognitive science to connectionism and then to embodied and situated cognition. The learning concepts identified earlier correspond with paradigms which in turn implicitly transport notions of knowledge, which radically changed from viewing knowledge as separate units to an ongoing knowledge process mediated through mental, physical, and social structures. This finally puts cognitive science in a shape where it can start conceptualizing learning "in the wild", thus also in educational systems. Prerequisite for successful interdisciplinary collaborations between cognitive and educational sciences is a clarification of viable concepts of learning and knowledge.

In educational processes the cognitive and educational scientists' research interests meet. Educational research has shown that the way individuals think about cognitive processes matters, because the way students think about knowledge determines the learning strategy they will employ.

Thus there is a deep, but intricate relation between concepts of learning, knowledge, and the way we conceptualize human cognition. Since the concepts involved may differ fundamentally they should be reflected explicitly in order to come to a fruitful interdisciplinary collaboration. While it may be naive to attempt a direct-to-classroom transfer of basic research findings to every day practice, it is still the teachers' implicit and explicit notions of learning and knowledge which determine student learning. It may be advisable to include an explicit reflection of underlying concepts their implications in teacher education.

\section{References}

Ansari, D., \& Coch, D. (2006). Bridges over troubled waters: education and cognitive neuroscience. TRENDS in Cognitive Sciences, 10 (4), 146-151.

Bechtel, W., Abrahamsen, A., \& Graham, G. (1998). The life of cognitive science. In: Bechtel, W. \& Graham, G. (Eds.), A companion to cognitive science, Oxford: Blackwell, 1-104.

Biggs, J. (1999). Teaching for Quality Learning at University. What the Student Does. SRHE and Open University Press.

Churchland, P., \& Sejnowski, T. J. (1993). The Computational Brain. Cambridge, Massachusetts: MIT Press.

Clark, A. (1995). Being There - Putting Brain, Body and World Together Again. Cambridge: MIT Press.

Clark, A. (1999). An embodied cognitive science?. TRENDS in Cognitive Sciences 3 (9), 345-351.

Dahaene, St. (1997). The Number Sense. How the Mind Creates Mathematics. Oxford: Oxford University Press.

Dreyfus, H. (1979). What Computers Can't Do. New York: MIT Press.

Entwistle, N., \& Ramsden, P. (1983). Understanding Student Learning. London: Croom Helm.

Fink, L. D. (2003). Creating Significant Learning Experiences: An Integrated Approach to Designing College Courses. Jossey-Bass.

Glenberg, A. M. (1997). What memory is for. Behavioral and Brain Sciences, 20, (1), 1-55.

Maturana, H. R. (1970). Biology of cognition. In: Maturana, H.R. \& Varela, F.J. (Eds.). Autopoiesis and cognition: the realization of the living. Dordrecht/Boston: Reidel Pub, 2-60.

Meltzoff, A. N., Kuhl, P. K., Movellan, J., \& Sejnowski, T. J. (2009). Foundations for a new science of learning. Science, 335 (5938), 284-288.

Perkins, D. (2008). Beyond Understanding. In: Land, R., Meyer, J.H.F. \& Smith, J. (Eds.). Threshold Concepts within the Disciplines. Rotterdam: Sense Publishers.

Peschl, M. F. (1994). Repräsentation und Konstruktion. Kognitions- und neuroinformatische Konzepte als Grundlage einer naturalisierten Epistemologie und Wissenschaftstheorie. Braunschweig/ Wiesbaden: Vieweg. 
PROBLEMS

OF EDUCATION

IN THE $21^{\text {st }}$ CENTURY

Volume 46, 2012

130 Reif, F. (2008). Applying Cognitive Science to Education. Thinking and Learning in Scientific and Other Complex Domains. Cambridge, Massachusetts: MIT Press.

Rumelhart, D., \& McClelland, J. (1986). Parallel Distributed Processing, Vol. 1 \& 2., Cambridge: MIT Press.

Schön, D. A. (1983). The reflective Practitioner - How professionals think in action. London: Temple.

Varela, F. J. (1990). Kognitionswissenschaft - Kognitionstechnik. Eine Skizze aktueller Perspektiven. Frankfurt am Main: Suhrkamp.

Vygotsky, L. S. (1978). Mind in Society. The Development of Higher Cognitive Processes. Cambridge, Massachusetts: Harvard University Press.

Wertheimer, M. (1982). Productive Thinking. Chicago: University of Chicago Press.

Zimbardo, P. G. (2004, 16. Auflage). Psychologie - Eine Einführung. Pearson Studium.

Advised by Vincentas Lamanauskas, University of Siauliai, Lithuania

Received: May 11, 2012

Accepted: August 25, 2012

Brigitte Römmer-Nossek MSc., Center for Teaching and Learning/ CTL, University of Vienna, Dr.-KarlLueger-Ring 1, 1010 Vienna, Austria.

E-mail: brigitte.roemmer-nossek@univie.ac.at 